\title{
Doctor of Dental Medicine
}

National Cancer Institute

\section{Source}

National Cancer Institute. Doctor of Dental Medicine. NCI Thesaurus. Code C39381.

The Doctor of Dental Medicine degree is the first-professional, postgraduate degree awarded for graduates who have completed a program of studies in dental medical science. The academic standard is equivalent to Ph.D. 